Disponível em
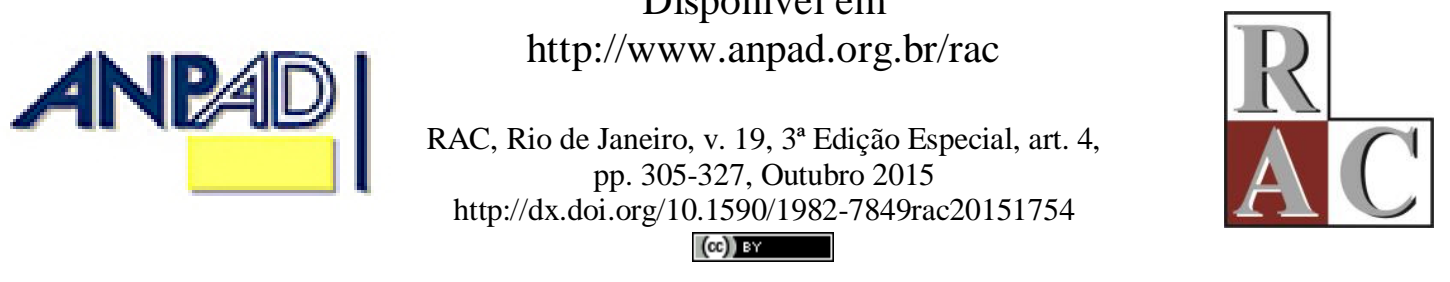

\title{
Análise sobre a Produção Acadêmica Brasileira em Comunidades de Prática
}

Analysis of Brazilian Academic Publication about Communities of Practice 


\title{
Resumo
}

O objetivo neste artigo foi analisar a evolução das publicações acadêmicas brasileiras a respeito do termo comunidades de prática, visando identificar, ao longo do tempo, o crescimento destas comunidades, assim como as transformações dos conceitos e suas utilizações nos textos acadêmicos. Para tanto, houve necessidade de discutir o surgimento e as derivações do conceito de comunidades de prática nos principais textos que abordam esse tema. Logo em seguida, foi apresentado um tópico sobre o percurso metodológico, no qual foram descritas as técnicas de bibliometria e análise contextual utilizadas na pesquisa desenvolvida. Os resultados mostram que os textos clássicos discutidos na parte teórica deste artigo são comumente referenciados (bibliometria) na produção acadêmica brasileira. Apesar disso, fica evidente que, em termos de disseminação, ampliação, restrição ou limitação na utilização do conceito de comunidades de prática, existem modificações terminológicas que vinculam esse conceito mais aos propósitos dos pesquisadores e de suas pesquisas do que, necessariamente, à compatibilidade desse termo ao que está estabelecido na literatura sobre o tema.

Palavras-chave: comunidades de prática; produção acadêmica brasileira; aprendizagem organizacional; aprendizagem formal e informal.

\begin{abstract}
The objective of this study was to analyze the evolution of Brazilian academic publication regarding the term communities of practice, to identify their growth over time, as well as transformations of the concept and conceptual forms used. To this end, we begin with the emergence of the concept of communities of practice through a general review of the classical texts that address the issue. Next, we detail our methodological approaches, which included bibliometric techniques and contextual analysis. The results show that the classic texts discussed in the theoretical part of this article are commonly referenced (bibliometrics) in Brazilian academic production. Despite this, it is evident that, in terms of dissemination, extension, restriction or limitation of the use of the communities of practice concept, there are conceptual modifications linking this concept more with researchers' purposes and their research than, necessarily, the compatibility of this concept to what is established in the literature on the theme.
\end{abstract}

Key words: communities of practice; Brazilian academic publication; organizational learning; formal and informal learning. 


\section{Introdução}

Os estudos sobre aprendizagem organizacional transcenderam há muito tempo os limites da psicologia e da sociologia nas organizações (Antonacopoulou, 2006; Gherardi, 2001; Ribes \& Bowker, 2009). São evidentes aqueles que incorporam em suas discussões artefatos e pressupostos teóricos provenientes, por exemplo, da economia (Boerner, Macher, \& Teece, 2001; LeBaron, 2012), da ciência política (Bunderson \& Reagans, 2011; Lapalombara, 2001), da antropologia (Amini \& Mortazavi, 2012; Czarniawska, 2001) e da filosofia (Gherardi \& Nicolini, 2001; Yakhlef, 2010), para uma análise mais diversificada dos fenômenos de geração do conhecimento e dos processos de aprendizagem. O campo de estudo sobre o conhecimento e a aprendizagem nas organizações ganha uma complexidade inerente à sua maturação (Antonello \& Godoy, 2011), assim como impõe limites na utilização indiscriminada de vários pressupostos teóricos em suas discussões epistemológicas (Mendes \& Antonello, 2011).

Para além dessa ambiguidade, os pontos conflitantes entre teóricos e estudiosos dos fenômenos da aprendizagem e do conhecimento nas organizações possuem sua gênese nas ideias de que as organizações aprendem e são o repositório do conhecimento (Argote \& Miron-Spektor, 2011; Levitt \& March, 1988) ou de que quem aprende são os indivíduos e o conhecimento está em ampla transformação (Argyris \& Schön, 1996; Campbell \& Armstrong, 2013). Ainda há aqueles que dizem ser os processos de aprendizagem e gestão do conhecimento atos formais nas organizações (Lui, 2009; Pawlowsky, 2001), e aqueles que pregam que o amplo processo de aprendizagem e difusão do conhecimento acontece nas relações informais (He \& McShane, 2010; Watkins \& Marsick, 1992).

Essa variedade nas vertentes teóricas sobre os fenômenos da aprendizagem e do conhecimento nas organizações permitiu diversificar as possibilidades de estudos para além do mainstream acadêmico de base funcionalista/positivista (Cunha, 2011; Mackenzie, 2012). Apesar de que muitas dessas abordagens são tratadas perifericamente no contexto dos estudos sobre aprendizagem e conhecimento, ainda assim elas têm causado impactos interessantes em termos de produção científica e sobre as possibilidades de práticas nas organizações (Eijkman, 2011; Grieves, 2008). Nesta linha, as temáticas que abordam os fenômenos da aprendizagem e do conhecimento nas vertentes informais e que possuem seus sustentáculos nas acepções teóricas provindas da sociologia, da filosofia, das ciências políticas ou da antropologia têm sido destacadas tanto em ternos de produção acadêmica quanto em termos de práticas nas organizações (Collen, 2012; Godoy \& Antonello, 2011).

Isso aconteceu com a ideia de comunidades de prática, que obteve ampla aceitação terminológica e teve desdobramentos nas interpretações e nas possibilidades de práticas impulsionadas no contexto das organizações.

Esse termo surge, inicialmente, no livro de Lave e Wenger (1991), não como uma discussão central, mas como a possibilidade de uma aprendizagem situada. As comunidades de prática é que possibilitam o que Lave e Wenger (1991, p. 34) vão chamar de "participação periférica legitimada". Logo depois dessa publicação em parceria com Jean Lave, Wenger (1998), observando o impacto do conceito de comunidades de prática no contexto acadêmico, publicou uma obra totalmente dedicada a essa concepção. Esses conceitos e as suas modificações serão abordados oportunamente no próximo tópico deste artigo.

O interessante do conceito de comunidades de prática foi sua ampla possibilidade de estudos, análises e práticas em várias áreas da ciência, como administração, educação, engenharia, ciência da informação, enfermagem, entre outras. Foi a partir dessa constatação que este artigo se efetivou. Primeiro, pela necessidade de avaliar a expansão quantitativa do termo comunidades de prática no Brasil. Segundo, pela intenção de compreender as formas conceituais de utilização deste termo no âmbito da produção acadêmica brasileira. Terceiro, pela importância de verificar as modificações deste conceito no contexto da pesquisa acadêmica brasileira. Dito isso, o objetivo neste artigo foi analisar a evolução das publicações acadêmicas brasileiras a respeito do termo comunidades de prática, visando identificar, ao longo do tempo, o seu crescimento, assim como as transformações do conceito e das formas conceituais utilizadas. 
Para realizar a análise proposta, uma profunda revisão da literatura acadêmica relevante é realizada e apresentada nas próximas seções. Assim, inicia-se examinando o surgimento e as derivações do conceito de comunidades de prática nos principais textos que abordam esse tema. Durante essa discussão teórica, o texto de Cox (2005) é constantemente retomado, pois esse autor se debruçou sobre as diferenças existentes entre os textos seminais, o que permite compreensões, no contexto deste artigo, sobre os elementos que subjazem essas obras. Logo em seguida, é apresentado um tópico sobre o percurso metodológico utilizado para analisar a evolução das publicações acadêmicas brasileiras sobre o termo comunidades de prática, onde são descritas as técnicas de bibliometria e análise contextual. Após essa discussão, num outro tópico, são avaliados os artigos selecionados através da pesquisa. Num primeiro momento, é dada ênfase aos aspectos quantitativos, que emergem possíveis a partir da bibliometria. Num segundo, o enfoque será sobre os aspectos qualitativos, em termos de conceitos e contextos utilizados nos artigos pesquisados. Por fim, algumas reflexões e conclusões são apresentadas.

\section{Os Conceitos de Comunidades de Prática}

O conceito de comunidades de prática surge inicialmente no trabalho de Lave e Wenger (1991), no entremeio às suas discussões sobre a aprendizagem situada. Esses autores, em 1991, procuraram trazer implicações importantes sobre a aprendizagem e o conhecimento conduzidos de forma informal e desenvolvidos em atividades práticas. A intenção foi mostrar que muitos dos atributos vinculados à aprendizagem e ao conhecimento estavam além da concepção psicológica (natureza eminentemente cognitiva), incorporando atribuições e peculiaridades da sociologia (onde o conhecimento e a aprendizagem ocorrem por meio das interações sociais). Além disso, um dos fatores importantes foi o de evidenciar que a aprendizagem e o conhecimento estavam sendo difundidos para além dos processos pedagógicos estabelecidos na interação aluno-professor em sala de aula. Para Lave e Wenger (1991), grande parte do processo de aprendizado e surgimento do conhecimento acontece de forma situada em ações práticas informais que se dão através da participação periférica legitimada (PPL).

O que esses autores entendem por participação periférica legitimada tem como pressuposto a ideia de que os novos integrantes participam em comunidades de prática, onde aprendem práticas de trabalho com os mais experientes. Com esse aprendizado, eles saem de uma participação periférica para uma plena participação dentro de uma comunidade. Lave e Wenger (1991) salientam que a PPL tem como pressuposto a relação entre novos e antigos integrantes, no sentido de compreender como esses novos integrantes fazem para atingirem a participação plena. Assim, o conceito de comunidades de prática, no texto de Lave e Wenger (1991), surge como um conjunto de relações entre pessoas, atividades e mundo, que é tangenciado por outras comunidades de prática.

Para apresentar o funcionamento das comunidades de prática, Lave e Wenger (1991) estudaram os casos de parteiras, alfaiates, açougueiros e alcoólatras anônimos. Os autores utilizam esses estudos para mostrar que a aprendizagem e o conhecimento vão além das técnicas e resultados obtidos, sendo produzidos e disseminados nas práticas de trabalho e nas relações pessoais e sociais. Por esse motivo, as comunidades de prática proporcionam localidade ao conhecimento e geram a aprendizagem.

No mesmo ano de publicação do trabalho de Lave e Wenger (1991), Brown e Duguid (1991) também escreveram sobre as comunidades de prática, mas numa vertente diferente. Apesar de não estarem distantes dos processos informais e situados de aprendizagem e conhecimento discutidos por Lave e Wenger (1991), Brown e Duguid (1991) salientam que as comunidades de prática contribuem mais com os processos de inovação do que com a reprodução das práticas existentes, como focou o trabalho de Lave e Wenger (1991). Para fundamentar essa tese sobre as relações informais serem mais de inovação do que de reprodução, Brown e Duguid (1991) apresentam a diferença entre o conhecimento canônico e o não canônico de uma organização, na tentativa de mostrar que o canônico é o que reproduz a prática existente. Isso porque o conhecimento canônico é escrito, lógico, fixado, imposto, individualizado e alienante, enquanto o não canônico é situado, oral, desqualificado, colaborativo, 
coletivo e direto. Assim, as comunidades de prática mais produzem as inovações do que reproduzem as ações existentes, pois elas geram os conhecimentos não canônicos.

O fato é que, ao analisar o trabalho de Brown e Duguid (1991), Cox (2005) salienta que esses autores consideraram as comunidades de prática com características homogêneas, como se todos os participantes tivessem as mesmas possibilidades e as mesmas relações de poder. Já no trabalho de Lave e Wenger (1991), embora não fiquem evidentes, diretamente, as discussões sobre as relações de poder, deve-se apontar que esses autores salientaram a existência de conflitos entre os integrantes das comunidades de prática, o que desconsidera a existência de características homogêneas nessas comunidades.

Brown e Duguid (1991), para explicar os processos de inovação, utilizaram o estudo etnográfico realizado por J. Orr, realizado nas dependências da Xerox. A descrição do trabalho de J. Orr possibilitou a Brown e Duguid (1991) dizerem que, no cotidiano de trabalho, a existência dessas comunidades de prática é fundamental para a geração de inovações. Cox (2005) mostra que, na verdade, J. Orr citou o conceito de comunidade ocupacional e não de comunidade de prática, pois o intuito deste autor (J. Orr) foi de apresentar que as situações e estruturas de trabalhos comuns permitem inovações. Com isso, as inovações descritas no trabalho de J. Orr, diferente do que evidenciam Brown e Duguid (1991), não surgem de práticas conjuntas, mas das estruturas e das situações de trabalho.

Tendo como foco essa diferença terminológica entre comunidades de prática e comunidade ocupacional/profissional, Cox (2005) lembra que o argumento de Brown e Duguid (1991) está baseado na rejeição das ações formalizadas no contexto de trabalho, mas de que, no texto de J. Orr, os manuais da Xerox surgem como recurso útil e formal nos processos desenvolvidos pelos funcionários de manutenção das máquinas. Cox (2005) salienta que, sendo úteis esses manuais, tanto para a mera reprodução de atividades quanto para sua evolução, os espaços para a existência das comunidades de prática, nas quais a geração de conhecimento não canônico é a regra, são limitados, o que fez com que J. Orr chamasse a comunidade estabelecida entre os funcionários de manutenção das máquinas da Xerox de comunidade ocupacional.

Para Brown e Duguid (1991), as comunidades de prática podem ser estimuladas pela organização, na promoção e no reconhecimento das relações informais geradas entre os funcionários. Apesar desses autores enfatizarem o lado informal das comunidades de prática, Cox (2005) salienta que, no trabalho de J. Orr, a Xerox resolveu dar sustentação às ações dos funcionários, no sentido de promover um maior relacionamento entre as comunidades ocupacionais, para que elas fossem capazes de difundir os conhecimentos às outras comunidades. Uma das atitudes, por exemplo, foi a disseminação de rádios transmissores entre os integrantes, para melhorar a comunicação entre eles. Essa ação, na avaliação feita por Cox (2005), não está ligada à criação ou ao estímulo para o surgimento de comunidades de prática - como prefere interpretar Brown e Duguid (1991), mas sim no suporte a essas comunidades.

Um conceito efetivo sobre o que é uma comunidade de prática surge no trabalho que Wenger (1998) produziu sozinho anos depois. Com a intenção de aprofundar o entendimento, assim como de apresentar a complexidade e as várias terminologias envolvidas no conceito de comunidades de prática, Wenger (1998) dedicou uma obra inteira à discussão sobre as comunidades de prática. Tendo em vista as várias críticas sofridas em seu trabalho com a Jean Lave, como a marginalização das relações de poder e também a falta de um conceito efetivo sobre o que é uma comunidade de prática, Wenger (1998) apropriou-se da teoria social da aprendizagem, mostrando que, nas comunidades de prática, estão envolvidos quatro temáticas: comunidades (aprender pertencendo), prática (aprender fazendo), significado (aprender pela experiência) e identidade (aprender sendo ou tornando-se).

Cox (2005) salienta que, no conceito de comunidades de prática concebido por Wenger (1998), surgem os seguintes indicadores: (a) são sustentadas por relações mútuas (harmoniosas ou conflituosas); (b) produzem formas compartilhadas de engajamento colaborativo no fazer as coisas; (c) identidades são mutuamente definidas; (d) ocorre ajustamento mútuo na discussão de um problema; (e) observa-se ausência de formalismo, dando a sensação de continuidade nas conversas e nas interações; (f) é 
prevalente saber o que os outros sabem, o que eles podem fazer e como eles podem contribuir para o empreendimento; e (g) emerge um discurso comum que reflete certa perspectiva sobre o mundo.

Tendo em vista esses indicadores, Wenger (1998) salienta que as comunidades de prática estão por toda parte e que, apesar de ser recente o conceito, as experiências envolvidas no contexto dessas comunidades são antigas. Isso porque as comunidades de prática estão na base das relações sociais. Para exemplificar esse fato, Wenger (1998) diz que um trabalhador organiza sua vida, no contexto de trabalho, em torno de seus colegas imediatos e clientes. Esse trabalhador pode exercer funções numa grande empresa, mas a sua prática está restrita a um grupo muito menor de outros funcionários e clientes. É a partir dessas relações de proximidade que surgem as pequenas comunidades, com suas características de informalidade. Por ser tão informal e ter raramente um foco explícito é que as comunidades de prática são também familiares.

Apesar dessa amplitude, Cox (2005) coloca em evidência que a origem do termo comunidade, no contexto da sociologia, denota grandes agrupamentos, de características estáveis, geograficamente situados, não intencionais e abrangentes. Cox (2005) mostra que, no conceito dado por Wenger (1998), a comunidade aparece com características totalmente diferentes daquelas do termo original, evidenciando os pequenos agrupamentos, as características dinâmicas, a localização difusa e a intencionalidade. Mesmo demonstrando essa disparidade conceitual, as implicações centrais de Cox (2005) estão alocadas na produção independente das comunidades de prática ao invés da produção conduzida pelas organizações. Cox (2005) salienta que, por mais paradoxal que possa parecer, o trabalho de Wenger (1998) foca a produção e o surgimento independentes das comunidades de prática, que são, no entanto, sustentadas pela racionalidade e por pressupostos organizacionais. Isso porque muito do conhecimento compartilhado nas comunidades de prática tem como repositório aqueles conhecimentos difundidos nas organizações.

Anos depois da publicação desse trabalho dedicado amplamente à discussão do conceito de comunidades de prática e dos elementos envolvidos e que dão suporte à existência dessas comunidades (identidade, pertencimento, sentido e prática), Wenger, McDermott e Snyder (2002) publicam outro trabalho, com conotações muitas vezes diversas daquelas discutidas por Wenger (1998). Isso decorre do fato de que o ponto focal dessa obra está na possibilidade de as organizações formarem as comunidades de prática. Essa mudança causou uma modificação conceitual, na qual a comunidade de prática passou a significar: "um grupo de pessoas que compartilham uma preocupação, um conjunto de problemas, uma paixão sobre um tópico ou que aprofundam seus conhecimentos e expertises numa área, interagindo de forma contínua" (Wenger, McDermott, \& Snyder, 2002, p. 4).

Cox (2005) elucida o quão vago se torna esse novo conceito de comunidades de prática surgido no trabalho de Wenger et al. (2002) em comparação com o trabalho anterior de Wenger (1998). Além disso, Cox (2005) realiza várias ponderações, ao dizer que Wenger et al. (2002) popularizam o conceito de comunidades de prática, ao mesmo tempo em que simplificam e tornam-no algo mercantil e totalmente alocado aos processos de gestão. As comunidades de prática passam a ser vistas como ferramentas de gestão, sendo que as ações podem e devem ser estimuladas pelas organizações. Essas mudanças causam deturpações evidentes no conceito de comunidades de prática, pois elas passam a ter como propósito aprender e compartilhar conhecimento em detrimento da realização do trabalho em si. Cox (2005) mostra que essa nova abordagem sobre as comunidades de prática evidencia que a prescrição para a gestão não se trata de criar estruturas para o funcionamento das comunidades surgidas informalmente, mas sim de promover novos agrupamentos de pessoas para trabalharem de forma conjunta (prática). As comunidades de prática, salienta Cox (2005), passam a existir como ferramentas de gerenciamento do conhecimento de funcionários e especialistas de uma empresa.

Para finalizar essa ampla discussão sobre o conceito de comunidades de prática, vale inserir uma tabela desenvolvida por Cox (2005, p. 19), na tentativa de resumir e elucidar algumas diferenças conceituais nos trabalhos de Lave e Wenger (1991), Brown e Duguid (1991), Wenger (1998) e Wenger et al. (2002). 
Tabela 1

\section{Resumo dos Conceitos nos Quatro Trabalhos Apresentados sobre Comunidades de Prática}

\begin{tabular}{|c|c|c|c|c|}
\hline Temáticas & $\begin{array}{l}\text { Lave e Wenger } \\
\qquad(1991)\end{array}$ & $\begin{array}{c}\text { Brown e Duguid } \\
\text { (1991) }\end{array}$ & Wenger (1998) & Wenger et al. (2002) \\
\hline $\begin{array}{l}\text { Conceito de } \\
\text { comunidades }\end{array}$ & $\begin{array}{l}\text { Grupo de pessoas } \\
\text { envolvidas em uma } \\
\text { atividade ou prática } \\
\text { coerente (ex.: } \\
\text { açougueiros, alfaiates, } \\
\text { etc.). }\end{array}$ & $\begin{array}{l}\text { Grupo informal de } \\
\text { trabalhadores } \\
\text { realizando a mesma } \\
\text { função ou função } \\
\text { semelhante. }\end{array}$ & $\begin{array}{l}\text { Conjunto de relações } \\
\text { sociais e significados } \\
\text { que crescem em torno } \\
\text { de um processo de } \\
\text { trabalho quando } \\
\text { apropriado pelos } \\
\text { participantes. }\end{array}$ & $\begin{array}{l}\text { Clube informal ou } \\
\text { grupo de interesse } \\
\text { especial dentro de } \\
\text { uma organização, } \\
\text { criada expressamente } \\
\text { para permitir a } \\
\text { aprendizagem } \\
\text { coletiva, estimulada } \\
\text { através dos processos } \\
\text { de gestão. }\end{array}$ \\
\hline $\begin{array}{l}\text { Visão sobre } \\
\text { aprendizagem }\end{array}$ & $\begin{array}{l}\text { Central, e vista como } \\
\text { ocorrendo através de } \\
\text { se tornar um membro } \\
\text { - a socialização de } \\
\text { novos membros pela } \\
\text { participação periférica } \\
\text { legitimada. }\end{array}$ & $\begin{array}{l}\text { Problema de } \\
\text { aprendizagem/ } \\
\text { colaboração, } \\
\text { resolução do grupo } \\
\text { através de contar } \\
\text { histórias }\end{array}$ & $\begin{array}{l}\text { Uma história de } \\
\text { aprendizagem } \\
\text { individual é a } \\
\text { identificação com as } \\
\text { diferentes } \\
\text { comunidades de } \\
\text { prática e trajetórias por } \\
\text { meio de comunidades. }\end{array}$ & $\begin{array}{l}\text { Aprendizagem } \\
\text { problema/solução } \\
\text { deliberadamente } \\
\text { construída reunindo } \\
\text { vários especialistas } \\
\text { em comunidades de } \\
\text { aprendizagem. }\end{array}$ \\
\hline
\end{tabular}

Nota. Fonte: Adaptado de Cox, A. (2005). What are communities of practice? A comparative review of four seminal works. Journal of Information Science, 31(6), 527-540. doi: 10.1177/0165551505057016

Da Tabela originalmente constituída por Cox (2005), dois tópicos foram salientados por estarem atrelados às intenções deste artigo, quais sejam: o conceito de comunidades de prática e a visão sobre a aprendizagem em cada uma dessas obras.

Na Tabela 1, em primeiro lugar, nota-se que o conceito de comunidades de prática emerge como algo distinto daqueles conceitos tradicionais, por exemplo, de grupo ou equipe de trabalho, que são formas organizacionais que produzem resultados formalmente planejados/programados pela organização. Por outro lado, o surgimento do conceito de comunidades de prática sempre esteve atrelado aos aspectos informais na teia de relacionamentos que se organiza no seio da comunidade de prática, para produzir conhecimentos não canônicos. De fato, mesmo Brown e Duguid (1991), que partem da existência das comunidades de prática no contexto de trabalho, e Wenger et al. (2002), que as consideram como iniciativa organizacional, salientam os aspectos informais na existência dessas comunidades.

Em segundo lugar, ao olhar a Tabela 1, pode-se observar que ela mostra a evolução conceitual que, de uma forma ou de outra, vai capturando as novas formas de utilização do conceito de comunidades de prática. Em termos gerais, constata-se que o conceito de comunidades de prática, sempre atrelado aos aspectos informais, mesmo quando visto no âmbito da empresa, tem como característica o interesse comum entre os participantes, que se revela em interesse de aprendizagem.

Apesar da falta de unicidade evidente no conceito de comunidades de prática, e que se revela nas variações conceituais discutidas anteriormente, a existência desse conceito coloca limites em suas apropriações. E esses limites estão condicionados, por exemplo, à forma como o grupo é visto (informal e/ou por interesses dos participantes) e às necessidades diversas de aprendizagem (informal, situada, colaborativa e na prática), que induzem à formação das comunidades de prática. Por esse motivo, nas discussões sobre as comunidades de prática, o foco é a aprendizagem. Desde os argumentos expressos por Lave e Wenger (1991) até o texto de Wenger et al. (2002), a aprendizagem é algo central. Nunca uma aprendizagem formal e de sala de aula, mas sim uma aprendizagem situada, colaborativa e na/da prática. 
Com isso, nota-se uma falta de clareza no conceito de comunidades de prática, no sentido do termo revelar-se ambíguo, posto que assume mais de um sentido e de uma possibilidade de interpretação, o que é um traço comum de conceitos novos, os quais evoluem desdobrando-se em variações que, com a maturidade, tendem à convergência e à unicidade. Esse processo evolutivo do conceito está refletido nas variações conceituais discutidas anteriormente, as quais, no entanto, são amparadas pela existência do conceito na colocação de limites em suas apropriações. Dito isso, o próximo tópico é o percurso metodológico.

\section{Percurso Metodológico}

A pesquisa desenvolvida no âmbito deste artigo se caracteriza como qualitativa. Por pesquisa qualitativa, Silverman (2010) entende que é aquela em que o pesquisador necessita ir além das contagens de opiniões ou dados estatísticos. Mesmo tendo como técnica de pesquisa, neste artigo, a bibliometria, o intuito de utilizá-la não é simplesmente para verificar os atributos quantitativos da produção acadêmica brasileira sobre comunidades de prática, mas sim para compreender, contextualmente, as modificações conceituais realizadas pelos pesquisadores a partir de seus objetos de estudo.

As técnicas de pesquisa utilizadas neste artigo foram a bibliometria e a análise contextual. Com isso, a bibliometria é o estudo das características quantitativas de produção, disseminação e uso da informação, assim como designa também os processos e os mecanismos avançados de busca on-line e técnicas de recuperação da informação (Marchant, 2009). Nesta mesma linha, Ferrara e Salini (2012) definem a bibliometria como a organização, a classificação e a avaliação quantitativa sobre padrões de publicação, provindas de cálculos matemáticos e estatísticos. Battisti e Salini (2013) colocam também que a bibliometria é o estudo de livros, documentos, revistas, autores e usuários, através de variáveis como o número de empréstimos, de citações ou de extensão de frases, tendo como método o ranking, a frequência ou a distribuição destas variáveis.

No caso da pesquisa aqui realizada, a bibliometria foi utilizada na avaliação de artigos relacionados a comunidades de prática. Assim, a pesquisa foi conduzida através de uma busca on-line no Google acadêmico (http://scholar.google.com.br, recuperado em 20, setembro, 2013) a partir das palavras-chave comunidades de prática e, no singular, comunidade de prática. Ferrara e Salini (2012) salientam que, nos dias atuais, os meios eletrônicos se tornaram importantes no processo de levantamento de materiais bibliográficos. A intenção de utilizar o Google acadêmico e não os sites de revistas e congressos é devida à amplitude da pesquisa, sendo que foi possível encontrar artigos em várias áreas da ciência. Além disso, como a intenção era selecionar apenas os artigos em arquivos completos e disponíveis na internet, uma das técnicas utilizadas juntamente com as palavras-chave foi inserir as extensões .pdf e .doc. Por isso, foram selecionados artigos somente vinculados à revista ou aos congressos, excetuando os artigos publicados pelo próprio autor ou por instituições cujo objetivo não seja um conteúdo científico. Franceschet (2010) salienta que, no levantamento bibliográfico, o pesquisador deve delimitar a busca, para que os resultados sejam mais precisos. Com isso, dado o objetivo da pesquisa, optou-se por considerar relevantes aqueles artigos que explicitam o termo comunidades de prática ou comunidade de prática em seus títulos. Isso porque, ao surgir esse termo no título, fica evidente a centralidade deste conceito no desenvolvimento do texto. Assim, não foram analisados os artigos em que o termo comunidades de prática aparece somente no corpo do artigo, pois isso poderia dificultar a análise contextual.

Foram, pois, selecionados para compor esta pesquisa 26 textos completos, dos quais 4 provenientes de congressos e 22 de periódicos. Esse número limitado de artigos em congressos está vinculado, possivelmente, à constatação de que muitos congressos não disponibilizam os artigos publicados em meio on-line, assim como muitos outros não disponibilizam abertamente o conteúdo dos artigos publicados. As peculiaridades dos artigos selecionados serão discutidas no próximo tópico. 
Além da bibliometria, como a intenção foi verificar também as possíveis mudanças conceituais, outra técnica utilizada foi a análise contextual. Na visão de Svensson e Doumas (2013), a análise contextual é utilizada como forma de traçar a perspectiva conceitual em cada contexto analisado. $\mathrm{O}$ intuito desta análise é o de verificar, por exemplo, como um conceito modifica-se quando utilizado em contextos diversos. Assim, a análise contextual possui dois focos. O primeiro é do contexto específico, que está relacionado à evidência dos aspectos concretos e qualitativos do texto. O segundo é o do contexto geral, em que há interferências dos pressupostos culturais que permeiam as situações em que o texto está imbricado. Svensson e Doumas (2013) salientam que muitas análises contextuais são realizadas em textos literários e não literários, e que são necessários, dependendo dos tipos de textos, focos nos elementos linguísticos. Como essa discussão linguística está além dos propósitos desta pesquisa, em termos de análise contextual, os focos abordados foram: o contexto específico (tema central do artigo) e o contexto geral (área da ciência) que contemplam os artigos pesquisados.

\section{Análise sobre a Produção Acadêmica Brasileira em Comunidades de Prática}

Os artigos selecionados foram publicados entre 2005 e 2013. Essa não foi uma delimitação intencional, pois a atualidade do termo permitiu identificar, através do Google Acadêmico, as primeiras publicações datadas de 2005. Apesar disso, alguns artigos já haviam sido publicados antes dessa data, mas em congressos que possuem os arquivos de ANAIS divulgados apenas em CD's. Devido a esse fato, esses artigos foram também negligenciados na pesquisa. Assim, a Tabela 2 mostra o ano e a quantidade de artigos publicados.

Tabela 2

Ano e Número de Publicação sobre o Tema Comunidades de Prática

\begin{tabular}{cc} 
Ano & Número de publicação \\
2005 & 2 \\
2006 & 3 \\
2007 & 4 \\
2008 & 6 \\
2009 & 2 \\
2010 & 2 \\
2011 & 3 \\
2012 & 2 \\
2013 & 2 \\
TOTAL & $\mathbf{2 6}$ \\
\hline
\end{tabular}

Além do número de artigos publicados, que teve seu ápice no ano de 2008 (6 dos 26 artigos selecionados), a busca através do Google Acadêmico possibilitou encontrar artigos de várias áreas da ciência. A seleção por área dos artigos levou em consideração o congresso ou periódico em que o artigo está publicado. Após esta constatação inicial, houve ainda a identificação do tema para, posteriormente, vincular o artigo a uma área específica da ciência. As áreas identificadas e a quantidade de artigos publicados por área estão dispostos na Tabela 3. 
Tabela 3

Número de Publicações por Áreas da Ciência

\begin{tabular}{cc}
\hline Área & Número de publicações \\
\hline Administração & 12 \\
Educação & 7 \\
Ciência da informação & 5 \\
Engenharia de produção & 1 \\
Enfermagem & 1 \\
TOTAL & $\mathbf{2 6}$ \\
\hline
\end{tabular}

A Tabela 3 mostra que a maioria dos artigos selecionados nesta pesquisa sobre comunidades de prática está alocada na área de Administração (12), seguidas pelas áreas de Educação (7) e Ciência da Informação (5). Outras duas áreas foram identificadas com apenas um artigo cada, que são: Engenharia de Produção e Enfermagem. Tendo constatado essas áreas, vale salientar os textos sobre comunidades de prática mais utilizados, de forma geral (todos os artigos) e de forma específica (por área da ciência), na tentativa de produzir um ranking das obras mais citadas e utilizadas na fundamentação e na conceituação de comunidades de prática. A Tabela 4 mostra o ranking das obras mais utilizadas em todos os 26 artigos que contemplam essa pesquisa. Apenas foram consideradas, nesta etapa de ranking geral, as obras que surgiram em dois artigos ou mais.

Tabela 4

\section{Ranking das Obras mais Citadas por Artigo Analisado}

Obra citada

$\begin{array}{cc}\text { Wenger } \text { et al. (2002) } & 15 \\ \text { Lave e Wenger (1991) } & 12 \\ \text { Wenger (1998) } & 10 \\ \text { Wenger e Snyder (2001) } & 4 \\ \text { Brown e Duguid (1991) } & 2 \\ \text { Wenger (2003) } & 2 \\ \text { Antonello e Ruas (2002) } & 2 \\ \text { Gropp (2003) } & 2 \\ \text { Tremblay (2004) } & 2\end{array}$

Essa Tabela 4 apresenta as obras que foram referenciadas no corpo do texto e na bibliografia dos artigos, e não na quantidade de citações feitas pelo(s) autor(es) no corpo do texto. Para tanto, a obra mais citada, que é a de Wenger et al. (2002), aparece referenciada em 15 dos 26 artigos analisados, seguido pelos textos de Lave e Wenger (1991), Wenger (1998) e Wenger e Snyder (2001). O texto de Brown e Duguid (1991), que possui algumas similaridades com o trabalho de Wenger et al. (2002), foi o menos citado na produção brasileira selecionada. Além desses trabalhos seminais, na Tabela 4 surgem mais três artigos que foram citados em pelo menos dois textos. Os artigos de Antonello e Ruas (2002) e de Gropp (2003) não foram identificados durante o levantamento dos artigos, pois estão publicados nos anais de um Congresso de Administração, cuja busca no Google Acadêmico não possibilitou o contato com os artigos completos. 
Focando agora as áreas em que os artigos surgem, vale mostrar as obras mais citadas, como forma de compreender quais dessas obras são as mais utilizadas pelos pesquisadores de cada área para fundamentarem seus conceitos de comunidades de prática. Assim, na Tabela 5, são apresentados os artigos mais citados (ranking) na área de Administração.

Tabela 5

\section{Ranking das Obras mais Citadas na Área de Administração}

\begin{tabular}{|cc|}
\hline Posição & Artigo \\
$\mathbf{1}^{\mathbf{o}}$ & Wenger e Snyder (2001) \\
$\mathbf{2}^{\mathbf{o}}$ & Wenger (1998) \\
$\mathbf{3}^{\mathbf{o}}$ & Wenger et al. (2002) \\
$\mathbf{4}^{\mathbf{o}}$ & Lave e Wenger (1991) \\
$\mathbf{5}^{\mathbf{0}}$ & Brown e Duguid (1991) \\
$\mathbf{6}^{\mathbf{0}}$ & Wenger (2003) \\
$\mathbf{7}^{\mathbf{0}}$ & Antonello e Ruas (2002) \\
$\mathbf{8}^{\mathbf{0}}$ & Gropp (2003) \\
$\mathbf{9}^{\mathbf{o}}$ & Tremblay (2004) \\
$\mathbf{1 0}^{\mathbf{0}}$ & Gazzoli (2006) \\
\hline
\end{tabular}

A Tabela 5, na mesma lógica de análise realizada na Tabela 4, mostra que a obra mais citada é a de Wenger e Snyder (2001), não discutida na parte teórica deste artigo, mas que é uma das únicas traduções desse tema que existe no Brasil, tendo em vista esses autores tradicionais. O texto de Wenger e Snyder (2001) possui uma proximidade com as ideias desenvolvidas em Wenger et al. (2002).

Já na área de ciência da informação, o ranking passou a ser outro, além do fato de que surgem outras obras citadas. Vale salientar que, para esse ranking, não foi utilizado a limitação da obra estar referenciada em dois ou mais artigos, pois a intenção foi verificar, para além dos principais textos utilizados, aqueles que contemplam as discussões desenvolvidas em cada área. Por esse motivo, na Tabela 5 surge mais um artigo, o de Gazzoli (2006), que não apareceu na Tabela 4. A única limitação está no ranking de no máximo 10 textos citados. Explicado isso, a Tabela 6 apresenta o ranking dos textos mais utilizados na área de Ciência da Informação.

Tabela 6

\section{Ranking das Obras mais Citadas na Área de Ciência da Informação}

\begin{tabular}{ccc}
\hline Posição & Artigo \\
$\mathbf{1}^{\mathbf{0}}$ & Lave e Wenger (1991) \\
$\mathbf{2}^{\mathbf{0}}$ & Wenger et al. (2002) \\
$\mathbf{3}^{\mathbf{0}}$ & Wenger (1998) \\
$\mathbf{4}^{\mathbf{0}}$ & Mengalli (2008) \\
$\mathbf{5}^{\mathbf{0}}$ & Cruz e Motta (2006) \\
$\mathbf{6}^{\mathbf{0}}$ & Silvio (1999) \\
$\mathbf{7}^{\mathbf{0}}$ & Sanz (2005) \\
\hline
\end{tabular}


Diferente da área de Administração, na área de Ciência da Informação a primeira posição é ocupada pelo trabalho de Lave e Wenger (1991), seguida do trabalho de Wenger et al. (2002) e Wenger (1998). Com certa semelhança da área de Administração, ainda os autores utilizam outras obras que estão difundidas em seus contextos acadêmicos.

No contexto dos trabalhos da área de Educação, ocorre uma nova mudança no ranking das obras citadas, ficando em primeiro lugar a obra de Wenger (1998), seguidas da obra de Lave e Wenger (1991) e Wenger et al. (2002). De forma semelhante às áreas discutidas anteriormente também surgem algumas obras produzidas ou que estão próximas da área de Educação. Esse ranking fica evidente na Tabela 7.

Tabela 7

Ranking das Obras mais Citadas na Área de Educação

\begin{tabular}{ccc}
\hline Ranking & Artigo \\
$\mathbf{1}^{\mathbf{0}}$ & Wenger (1998) \\
$\mathbf{2}^{\mathbf{o}}$ & Lave e Wenger (1991) \\
$\mathbf{3}^{\mathbf{o}}$ & Wenger et al. (2002) \\
$\mathbf{4}^{\mathbf{0}}$ & Barab e Duffy (2000) \\
$\mathbf{5}^{\mathbf{0}}$ & Mengalli (2006) \\
\hline
\end{tabular}

Como as obras nas áreas de Engenharia e Enfermagem não foram significativas para estabelecer esse ranking, não houve a necessidade de realizar uma tabela específica para essa apresentação. Mesmo assim, é de suma importância citar as obras utilizadas para fundamentar o conceito de comunidades de prática em cada um desses artigos vinculados a essas áreas. Na área de Engenharia foram dois textos citados: Wenger et al. (2002) e Roediger e McDermott (1999); e, na área de Enfermagem, apenas um: Wenger et al. (2002). Vale salientar que tais referências levam em consideração a existência da palavra comunidades de prática em seu título, excetuando os artigos que abordam essa temática de forma diversa e não centralizada.

As Tabelas 4, 5, 6 e 7 deixam evidentes um fator importante, que se refere às obras mais citadas no texto. Algumas dessas obras são provenientes de publicações em anais de congresso (Antonello \& Ruas, 2002; Cruz \& Motta, 2006; Gazzoli, 2006; Gropp, 2003), em sites especializados (Mengalli, 2008; Silvio, 1999) e dissertações de mestrado (Mengalli, 2006). Quantitativamente, essas obras, provenientes de outros meios que não os periódicos ou livros, representam cerca de $40 \%$ das obras mais citadas nos artigos avaliados. Isso demostra que o tema é recente no Brasil, o que tem estimulado os pesquisadores brasileiros a fundamentarem suas concepções teóricas em textos provenientes de fontes diversas que não os periódicos qualificados.

Outra explicação possível é a de que, no Brasil, os artigos publicados em anais de congressos sempre foram amplamente utilizados nas discussões teóricas, devido ao fato de que eram artigos rapidamente publicados e com discussões e temas atuais. Como o tempo de publicação de um artigo em um periódico no Brasil sempre foi longo ( 2 a 3 anos), muitos estudiosos utilizavam-se dos artigos de anais de congressos como forma de constituição dos referenciais teóricos. Por esse motivo, provavelmente, no levantamento realizado nesta pesquisa, houve o surgimento destes artigos específicos, sites e dissertações entre os mais citados. Essa constatação não está ligada à qualidade dos artigos analisados, mas é uma evidência importante de que o tema é recente ou ainda incipiente, o que atesta a necessidade de uma análise contextual sobre os conceitos centrais existentes nesses artigos.

Dito isso, é necessário elucidar um quadro sobre o contexto em que os autores utilizam o termo comunidades de prática, ou seja, sobre que tema ou prática em si o conceito de comunidades de prática está relacionado. Isso evidenciando apenas o título dos artigos. Assim, a Tabela 8 mostra a área e os temas ou práticas em que a ideia de comunidades de prática foi abordada. 
Tabela 8

\section{Área e Tema Central dos Artigos Analisados}

\begin{tabular}{|c|c|}
\hline Área & Tema central \\
\hline Administração & $\begin{array}{l}\text { (01) Formação gerencial em cursos de pós-graduação } \\
\text { (02) Colaboração reflexiva em ações organizacionais } \\
\text { (03) Comunidade de consultores } \\
\text { (04) Surgimento de comunidades de prática } \\
\text { (05) Somos uma comunidade de prática? } \\
\text { (06) Espaço interativo na relação universidade-empresa } \\
\text { (07) Comunidade virtual de prática? } \\
\text { (08) Comunidade de prática em arranjos produtivos locais } \\
\text { (09) Aprendizagem em comunidades de prática } \\
\text { (10) Equipes e comunidades de prática } \\
\text { (11) Comunidades de prática de consultores } \\
\text { (12) Cultura organizacional e comunidades de prática }\end{array}$ \\
\hline Educação & $\begin{array}{l}\text { (13) Novo profissional em comunidades de prática } \\
\text { (14) Comunidade virtual de prática e a mudança educacional } \\
\text { (15) Tecnologia da Informação na educação infantil } \\
\text { (16) Comunidade virtual de prática e a pesquisa na educação } \\
\text { (17) Comunidades de práticas pedagógicas universitárias } \\
\text { (18) Comunidades de prática e comunidades virtuais } \\
\text { (19) Comunidades de prática e a busca do conhecimento }\end{array}$ \\
\hline Ciência da informação & $\begin{array}{l}\text { (20) Second Life como comunidades de prática } \\
\text { (21) Aprendizagem em unidade de informação } \\
\text { (22) Comunidade virtual de prática e aprendizagem } \\
\text { (23) Modelo para reputação em comunidade de prática } \\
\text { (24) Aprendizagem social através das comunidades de prática }\end{array}$ \\
\hline Engenharia de produção & (25) Gestão do conhecimento organizacional \\
\hline Enfermagem & (26) Prestação de cuidados de saúde primários \\
\hline
\end{tabular}

A partir da Tabela 8 é que serão expostos os conceitos centrais utilizados em cada artigo selecionado, com o intuito de avaliar, de forma contextual, a relação conceitual com o tema central abordado nos artigos. Para isso, foi utilizada uma numeração de identificação do tema e o seu conceito correlato, como forma de minimizar o espaço utilizado para a identificação do artigo. Assim, os números utilizados na Tabela 8 identificam os conceitos nas tabelas posteriores.

Na Tabela 9 são elucidados, de forma sucinta, os conceitos encontrados ou mesmo que apresentam de forma geral a ideia que o(s) autor(es) possu(em) sobre o que é uma comunidade de prática. Esses conceitos, após uma análise contextual em cada artigo, foram transpostos para essa Tabela 9 na forma exata em que eles se encontram nos artigos referenciados (número do artigo). Essa tabela apresenta apenas os artigos da área de Administração. 
Tabela 9

\section{Conceitos Centrais Identificados sobre Comunidades de Prática nos Artigos Analisados da Área de Administração}

\section{No Art. Conceito central identificado de comunidades de prática (Administração)}

(01) Um grupo interdependente de pessoas com conhecimento complementar e que interagem através de (recursos e outras) relações.

(02) Uma comunidade de prática constitui-se num ambiente que sustenta suficiente engajamento voluntário e mútuo entre seus membros, objetivando, por meio da busca de empreendimentos comuns, a partilha de conhecimentos e geração de aprendizagem.

(03) Em síntese, são grupos de pessoas ligadas informalmente pelo conhecimento especializado e compartilhado, e pela paixão por um empreendimento conjunto.... Inevitavelmente ... seus participantes compartilham experiências e conhecimento com liberdade e criatividade, incentivando novas abordagens para os problemas.

(04) Uma comunidade de prática é caracterizada, sobretudo, pela oportunidade de seus membros desenvolverem suas capacidades, construindo conhecimento por meio do intercâmbio mútuo de múltiplas experiências, bem como por meio da incorporação de uma competência socialmente legitimada.

(05) O que caracteriza uma comunidade de prática é a reunião de profissionais de atividades comuns ou próximas, dispostos a regular sua prática, de acordo com as mesmas normas de conduta e de proficiência operativa.

(06) Uma comunidade de prática não é apenas um grupo delimitado por alguma característica, mas pessoas que aprendem, constroem e fazem a gestão do conhecimento... As comunidades agregam valores às organizações de diversas formas: elas colaboram na direção de estratégias, dão início a novas linhas de negócios, resolvem problemas rapidamente, transferem as melhores práticas, desenvolvem habilidades profissionais, ajudam a organização a recrutar e a reter talentos etc.

(07) Comunidades de prática são pessoas que compartilham uma preocupação, um conjunto de problemas ou uma paixão sobre um assunto, e aprofundam seus conhecimentos e experiências numa área interagindo de forma contínua.... Um grupo cujos membros se envolvem em compartilhar e aprender, tendo como base seus interesses comuns.

(08) Enfim, os membros de uma CoP trabalham juntos, olham uns pelos outros, conversam entre si, trocam informações e opiniões e são, diretamente, influenciados pelo entendimento mútuo como uma questão de rotina. Depreende-se daí que CoPs podem ser pensadas com base em histórias compartilhadas de aprendizagem e colaboração. Para que a prática nessas comunidades seja um processo intencional, seus membros realizam tarefas conjuntas, negociam novos significados e aprendem uns com os outros, compartilhando suas competências com os novos entrantes.

(09) Grupos de praticantes que compartilham objetivos e desafios interagem regularmente, aprendem pelos outros e com os outros, e desenvolvem habilidades para lidar com tais desafios e atingir seus objetivos. As pessoas são ligadas umas às outras pelo engajamento mútuo em atividades compartilhadas, orientadas por um senso de propósito comum, de empreendimento coletivo desenvolvendo um repertório próprio.

(10) Comunidades de prática emergem de um desejo comum entre os membros de compartilhar conhecimentos dentro de uma área de interesse, aprofundando seus conhecimentos através de oportunidades regulares para a troca de informações, experiências, ideias e reflexões.

(11) Comunidades de prática de consultores ocorrem através do contato com outros consultores para discussão e reflexão sobre suas práticas e problemas, promovendo novos conhecimentos e inovações, desenvolvendo novas práticas de intervenções comuns e gerando novas teorias.

(12) Comunidades de prática são para desenvolver as competências dos participantes em gerar e trocar conhecimentos.

Tendo em vista os artigos da área de Administração, é possível identificar uma polissemia conceitual, apesar de alguns atributos vinculados às comunidades de prática estarem evidentes (relações 
entre pessoas, conhecimento, aprendizagem, experiências compartilhadas, entre outras). Essa polissemia conceitual, levando em consideração os temas centrais de cada artigo (expostos na Tabela 8), mostra que os conceitos de comunidades de prática sofreram modificações evidentes para uma melhor alocação com os pressupostos centrais de cada pesquisa realizada. Talvez pela dificuldade, salientada na discussão teórica, de os principais autores que discutiram sobre as comunidades de prática não possibilitarem um conceito claro e acabado, é que surgem as oportunidades de realização das várias apropriações do termo, observadas nos artigos em análise, as quais, a princípio, extrapolam os limites atribuídos aos conceitos de comunidades de prática. Porém, deve ser notado que, de acordo com a discussão teórica já realizada e mesmo no entremeio à falta de clareza conceitual, os autores clássicos possibilitam distinções entre as comunidades de práticas e outras formas de agrupamentos nas organizações ou fora dela, colocando limites claros ao conceito de comunidades de prática.

Por esse motivo, um terceiro texto que surge muito referenciado nos trabalhos acadêmicos em Administração, é o de Wenger et al. (2002). Neste texto, fica claro que as comunidades de prática diferem das outras formas de organização comum entre pessoas, pois estão focadas na troca e no compartilhamento de conhecimentos e nas formas sociais de aprendizagem (aprender juntos). Nesta linha, as comunidades de prática diferem dos departamentos formais, das equipes operacionais e de projetos, pois os membros se integram por motivações específicas, muitas vezes ligadas à especialidade ou à paixão por alguma coisa. Nos departamentos formais, nas equipes operacionais e de projetos, há a união direcionada pela organização ou pela gerência na formação desses grupos. Além disso, tais grupos estão direcionados a objetivos pré-determinados pela organização ou pela gerência. Isso não quer dizer que as comunidades de prática não possuam objetivos, pelo contrário, mas que esses objetivos surgem de forma difusa, e são vinculados à paixão ou à especialidade dos membros.

O processo de aprendizagem ou conhecimento em uma comunidade de prática tem que, necessariamente, passar pela prática. Esse conceito de prática, em muitos dos textos analisados, foi tangenciado ou mesmo esquecido (salvo algumas exceções). Numa comunidade de prática, não se aprende apenas compartilhando ou comunicando ideias (experiências), mas fazendo, sendo e pertencendo, conforme está enfatizado nos dois textos mais utilizados na área de administração (Wenger, 1998; Wenger \& Snyder, 2001).

Wenger (1998) considera que as comunidades de prática possuem três características cruciais, que são: (a) o domínio, (b) a comunidade e (c) a prática. O domínio, como salientado anteriormente, tem como característica, além do processo conjunto de aprendizagem e troca de conhecimento, as competências dos participantes na comunidade. A comunidade está vinculada às relações conjuntas de aprendizagem, mas isso não exige que todos trabalhem juntos. $\mathrm{O}$ fato é que o aprendido se torna parte da prática dos participantes e, ao executarem suas tarefas individuais, há a manifestação desse aprendizado. A prática está no fato de que os integrantes de uma comunidade de prática não apenas possuem interesses comuns, mas suas práticas de trabalho ou sociais são semelhantes. Wenger (1998) salienta que só há comunidades de prática quando os participantes compartilham modos de fazer, experiências, histórias, formas de abordagens de problemas recorrentes, entre outras ações.

Esse fato limita muito a utilização do conceito, por exemplo, em conteúdos ou agrupamentos onde o objeto é apenas desenvolver ideias ou gerar conhecimento. A Tabela 9 mostra exatamente que, apesar de os estudiosos dos artigos analisados na área de Administração compartilharem de textos ou teorias próximas sobre comunidades de prática, ainda assim possibilitam uma polissemia conceitual, o que dificulta evidenciar quais são as características centrais que devem ser referenciadas em uma comunidade de prática.

Na Tabela 1, que trata dos resumos sobre os conceitos de comunidades de prática e formas de aprendizagem nas obras descritas no referencial teórico, é possível constatar que, dependendo do conceito utilizado, a maneira de conceber a aprendizagem se altera, mas essas formas mantêm proximidades e relações (informal, situada, colaborativa, etc.). Porém, em muitos textos analisados, esse cuidado não foi evidenciado, pois há predomínio de algumas obras nas discussões teóricas dos artigos analisados que não condizem com as formas de aprendizagem adotadas pelos autores clássicos 
utilizados. Mesmo realizando uma análise geral - tendo em vista as Tabelas 5 e 9 - existem diferenças conceituais na Tabela 9 que estão muito além do evidenciado na Tabela 5.

Isso não quer dizer que todos os artigos analisados estão incoerentes em relação ao significado do termo comunidades de prática, pois uma leitura minuciosa dos conceitos centrais descritos na Tabela 9 - tendo como referência a parte teórica deste artigo - mostra que muitos elementos que distinguem as comunidades de prática de outras formas de relações interpessoais estão presentes. O que é necessário frisar, a partir da análise contextual, é que os conceitos utilizados pelos autores de artigos sob análise sofreram modificações que muitas vezes deturpam as ideias originais sobre comunidades de prática, conforme apresentadas na literatura acadêmica relevante, para estarem relacionados às intenções dos autores e dos propósitos de suas pesquisas. Isso não seria um problema se essas modificações não colocassem - como já salientado - tais conceitos com características muito próximas aos conceitos tradicionais de equipes e grupos de trabalho.

No caso dos artigos provenientes das outras áreas, somente nos textos das áreas de Engenharia de Produção e Enfermagem é que surge o texto de Wenger et al. (2002), como fundamentação do conceito central do artigo. Isso pode ser explicado pelo contexto em que os dois artigos se inserem, pois ambos fazem parte de estudos sobre organizações, apesar dos temas diferenciados. Na área de educação e ciência da informação, o foco das discussões sobre comunidades de prática é outro, e os textos de Lave e Wenger (1991), Tabela 6, e Wenger (1998), Tabela 7, tomam a cena na fundamentação conceitual. A Tabela 10 apresenta os conceitos provenientes dos artigos das outras áreas da ciência (Educação, Ciência da Informação, Engenharia de Produção e Enfermagem).

Tabela 10

Conceitos Centrais Identificados sobre Comunidades de Prática nos Artigos Analisados das Áreas de Educação, Ciência da Informação, Engenharia de Produção e Enfermagem

\section{No Art. Conceito central identificado de comunidades de prática (outras áreas)}

(13) É um espaço em que a interação, o registro e a organização permitem que a construção e a gestão sejam baseadas no conhecimento; o domínio é o assunto é necessário para a interação e a integração dos partícipes, uma articulação com a gestão escolar; a prática é a contribuição, a troca e o aprendizado - o pomo do trabalho com a gestão em instituições educacionais - que, com o outro, será negociado e renegociado, assim como emerge a significação e a ressignificação da prática.

(14) É uma entidade que pode ser descrita com características reconhecíveis e em que o seu aspecto estrutural é determinante, ou, então, como uma entidade com valor fundamentalmente simbólico, de estabelecimento de limites e, por isso, intencional, devendo ser descrita também a partir de dentro da experiência dos seus participantes.

(15) As comunidades de prática surgem para dar lugar a um espaço comum, onde um grupo de indivíduos procura atingir um ideal de uma forma espontânea e regular. As comunidades possuem características específicas, que a definem e se fazem reconhecer no meio de outras comunidades. Cada uma delas surge e se desenvolve assumindo um carácter presencial ou virtual, apoiado pelas TIC.

(16) Comunidade virtual de prática envolve professores e pesquisadores com o intuito de criar condições para um duplo movimento, da pesquisa para a prática e da prática para a pesquisa, por meio da participação de seus membros em relações de engajamento mútuo.

(17) Comunidades de práticas pedagógicas universitárias são configuradas com base em uma problemática comum, que reúne docentes atuantes nos mesmos contextos formativos.

(18) Comunidades de prática são grupos de pessoas compartilhando conhecimentos, procurando aprofundar seus conhecimentos interagindo de forma permanente, através de meios físicos ou virtuais.

(19) Comunidade de prática é o veículo através do qual ocorre a aprendizagem. 
Tabela 10 (continuação)

\section{No Art. Conceito central identificado de comunidades de prática (outras áreas)}

(20) É um grupo de pessoas que partilha um interesse e que se junta para criar uma prática em torno desse tópico para aprenderem, compartilharem e gerarem novos conhecimentos. Exemplos de comunidades de prática podem ser consultores que se especializaram em mudança organizacional, investigadores envolvidos na decodificação do ADN, engenheiros envolvidos na perfuração de poços de petróleo.

(21) Grupos formados em torno da prática de sua profissão, ligados pela necessidade de partilhar experiências e desenvolver um conhecimento coletivo. As pessoas necessitam trocar experiências com seus colegas e envidar esforços para se reunir e partilhar histórias, visando construir um conhecimento que os ajude a enfrentar os problemas que surgem.

(22) É um grupo de pessoas que compartilham um desafio prático num determinado contexto, interagindo regularmente e aprendendo, uns com os outros, formas de enfrentar os desafios. Em outras palavras, esse grupo desenvolve uma prática compartilhada.

(23) Uma comunidade de prática pode ser tanto um local para a aquisição quanto para a criação de conhecimento. Muitas vezes, os indivíduos podem compartilhar conhecimento disponibilizando artefatos de interesse, e o sistema de apoio à comunidade recomendar artefatos com base nas avaliações feitas pelos membros.

(24) Comunidades de prática oferecem suporte à interação social ao mesmo tempo em que estimulam o processo de participação e aprofundamento do domínio da aprendizagem através das tecnologias da informação

(25) Comunidades de prática emergem de um desejo comum entre os membros de compartilhar conhecimentos dentro de uma área de interesse, aprofundando seus conhecimentos através de oportunidades regulares para a troca de informações, experiências, ideias e reflexões. Em outras palavras, o que une os membros da comunidade de prática é o interesse por um tópico ou disciplina comum.

(26) Consideramos as COPs verdadeiros «Espaços Humanos», criadores de profissionais experientes e críticos, logo cidadãos, que narram e dão sentido ao conhecimento, à aprendizagem e às competências, e que visam à construção de soluções e à geração de valor, traduzíveis em cuidados de saúde, para as populações que servem.

Como acontece com os artigos da área de Administração, nas outras áreas evidentes na Tabela 10 ocorre também uma polissemia conceitual sobre o que são comunidades de prática. Além disso, há uma nítida relação entre o conceito central dado pelos autores (Tabela 10) frente aos temas trabalhados em cada artigo (Tabela 8). Numa análise feita entre as Tabelas 9 e 10, a confusão conceitual é ainda maior, e isso dificulta traçar características gerais sobre o que é uma comunidade de prática. Um facilitador da compreensão dos conceitos, nesta análise contextual, é a existência da Tabela 8, que evidencia as áreas da ciência e os temas centrais dos artigos. Tais temas centrais possibilitam compreender, em detrimento das discussões teóricas, os conceitos que integram as Tabelas 9 e 10. Ou seja, em muitos casos, os conceitos elaborados pelos autores só são passíveis de compreensão se nos temas estiverem manifestos. Isso porque, somente a partir das discussões teóricas e da evidência dos textos mais citados (bibliometria) no conjunto dos artigos, não é possível uma análise mais apurada do que esses autores entendem por comunidades de prática.

O interessante de analisar antigos provenientes de áreas distintas está na forma de apropriação dos termos e dos conceitos. Na Administração fica evidente a preocupação, em torno do conceito dado de comunidades de prática, sobre o conhecimento e a aprendizagem, assim como sobre a existência de grupos de trabalho, interesses específicos, competências, entre outros. Na área de Ciência da Informação, além de algumas características próximas à administração, ainda as comunidades de prática surgem em relações evidentes com as tecnologias da informação e os programas computacionais que possibilitam os vínculos entre os integrantes de uma comunidade. $\mathrm{Na}$ área de Educação, surgem preocupações voltadas para a utilização de tecnologias da informação e programas computacionais, mas com foco nos processos de aprendizagem e na disseminação do conhecimento aos educadores e 
educandos. Na área de Engenharia de Produção, apesar de ser apenas um artigo, a comunidade de prática surge voltada para a gestão do conhecimento. Por fim, na área de Enfermagem, tal comunidade está focada nos cuidados hospitalares. Essas duas últimas áreas, numa proximidade com a área de Administração, também conceituam comunidades de prática, tendo como foco a aprendizagem, o conhecimento e a relação entre pessoas.

O que torna evidente nesta análise conceitual é, muitas vezes, uma deturpação do conceito de comunidades de prática, que vai além ou aquém dos propósitos iniciais de surgimento do conceito. Por esse motivo, em muitos casos, deveriam ser utilizados ou empregados outros conceitos como, por exemplo: comunidades de aprendizagem, comunidades de conhecimento ou comunidades de profissionais, assim como grupos ou equipes de trabalho. O cuidado que teve J. Orr em sua obra, como salientou Cox (2005, p. 530), ao evidenciar "comunidade ocupacional", referindo-se às relações informais de aprendizagem entre os funcionários da Xerox, deveria ser levado em consideração no Brasil. Apesar da não clareza conceitual evidente nos primeiros trabalhos sobre comunidades de prática, ainda assim essas comunidades possuem suas peculiaridades, como já salientado, o que limita a utilização indiscriminada do termo. Além disso, mesmo com a elucidação de Wenger (1998) de que existem comunidades de prática em todos os lugares, isso não significa que tudo pode ser considerado comunidades de prática. Ainda porque uma das características principais para a existência de uma comunidade de prática é a sua informalidade, que pode ser sustentada ou impulsionada pelas organizações, mas sempre deve ocorrer de forma deliberada por seus integrantes.

As comunidades de prática, expõem Wenger et al. (2002), são distintas das comunidades de interesse e das redes informais. As comunidades de interesse focam as necessidades individuais em determinado período. Quando ocorre o desinteresse, os membros saem e outros surgem, mas com propósitos bem específicos. As comunidades de prática também possuem interesses, mas há o comprometimento dos membros com as ajudas mútuas, a aprendizagem e os conhecimentos compartilhados. As comunidades de prática possuem um nível de integração entre os membros muito maior do que as comunidades de interesse. No caso das redes informais, há, nas comunidades de prática, um nível maior de formalização de suas ações, o que não ocorre nessas redes. O funcionamento nas redes informais está ligado às relações de parentesco ou amizade entre membros, o que não se dá comumente nas comunidades de prática.

Outro fator que está em jogo nas discussões sobre as comunidades de prática refere-se aos processos de aprendizagem e difusão do conhecimento. O termo comunidades de prática, apesar de suas modificações nos últimos textos clássicos, surge como possibilidade de estimular os processos de aprendizagem e difusão do conhecimento que ocorrem informalmente. Sendo estimulada ou não pelas organizações a existência ou sustentação das comunidades de prática, ainda assim os focos sobre a aprendizagem e o conhecimento devem estar assentados sobre essa informalidade. Apesar do trabalho de Wenger et al. (2002) aproximar as comunidades de prática dos processos formais de gestão, ainda assim os atributos de informalidade são evidentes. Isso limita a utilização do conceito de comunidades de prática em que a aprendizagem é vista como algo formal. Por isso, em muitos casos, utilizar a denominação comunidades de aprendizagem ou comunidades virtuais de aprendizagem seria mais coerente do que o termo comunidades de prática. Ainda nessa linha, seria necessário observar (conforme descrito resumidamente na Tabela 1) como a aprendizagem é compreendida no texto clássico utilizado na fundamentação teórica dos artigos.

Para finalizar, o conceito de comunidades de prática está além da fronteira organizacional, atingindo membros de outras organizações. Na filiação a uma comunidade de prática, a restrição a uma organização ou a um grupo ocupacional causa problemas evidentes, pois existem termos mais apropriados e bem difundidos, como os de grupo de trabalho, equipes de trabalho ou comunidades ocupacionais. Se a formação é estimulada ou sustentada pela organização, e essa formação está contida pelos funcionários de apenas uma organização, então não há a representação evidente de uma comunidade de prática. 


\section{Conclusões}

O objetivo deste artigo foi analisar a evolução das publicações acadêmicas brasileiras a respeito do termo comunidades de prática, visando identificar, ao longo do tempo, o seu crescimento, assim como as transformações do conceito e das formas conceituais utilizadas. O levantamento aqui realizado, além de evidenciar a produção brasileira sobre o tema comunidades de prática, ainda contribuiu para uma análise contextual desse termo, como forma de avaliar as mudanças, modificações, polissemias e características centrais encontradas na produção acadêmica brasileira. Neste sentido, a utilização de duas técnicas de pesquisa, a bibliometria e a análise contextual permitiram entender que, mesmo detectando os textos mais citados no contexto dos artigos pesquisados, não é possível compreender os conceitos de comunidades de prática utilizados sem a evidência dos temas e dos propósitos dos autores.

Por esse motivo, ao invés de encontrar uma coerência interna nos conceitos difundidos nos artigos pesquisados, ou mesmo uma repetição conceitual, o que ficou evidente foi uma polissemia vinculada ao tema central de cada artigo e não à diversidade de obras utilizadas para fundamentação conceitual. Isso mostra que o conceito de comunidades de prática passa por uma apropriação específica de cada autor. Essa apropriação não seria problemática se o conceito de comunidades de prática não possuísse características de equipes, grupos de trabalho ou comunidades ocupacionais, como é possível detectar em alguns conceitos descritos nas Tabelas 9 e 10. Claro que um conceito está sempre aberto a novas interpretações, mas é importante frisar que estes possuem características centrais que os tornam distintos. São essas características que, em alguns casos, não ficaram evidentes, e todos os esforços dos autores clássicos para distinguirem as comunidades de prática de outras organizações ou relações informais foram negligenciados.

Apesar das limitações explicitadas nesta pesquisa, principalmente em relação à quantidade de artigos analisados e ao curto período para uma análise bibliométrica (2005 até 2013), ainda as contribuições podem refletir a necessidade de maturidade na produção acadêmica brasileira. A utilização de um termo como o de comunidades de prática reflete bem, numa avaliação contextual dos conceitos e temas abordados, as inúmeras possibilidades de adequações conceituais vinculadas aos interesses dos pesquisadores ou estudiosos. Se, por um lado, isso mostra a criatividade e as possibilidades teóricas e de temas de pesquisa, por outro lado, pode incorrer em deturpações conceituações que dificultam a compreensão das reais intenções dos autores no processo de utilização e difusão de um conceito específico. Foi nesta linha que a análise contextual permitiu demonstrar a necessidade de parcimônia e maior cuidado no processo de apropriação conceitual.

Assim, o conceito de comunidades de prática emerge como algo distinto daqueles conceitos tradicionais, por exemplo, de grupo ou equipe de trabalho, que são formas organizacionais que produzem resultados formais. O surgimento do conceito de comunidades de prática sempre esteve atrelado aos aspectos informais dos relacionamentos para produzir conhecimentos não canônicos. Além disso, pode-se observar que a evolução no conceito de comunidades de prática possibilitou novas formas de utilizá-lo.

Apesar da falta de unicidade evidente no conceito de comunidades de prática que se revela nas variações conceituais discutidas anteriormente, a existência desse conceito coloca limites em suas apropriações. E tais limites estão condicionados, por exemplo, à forma como o grupo é visto (informal e/ou por interesses dos participantes) e às necessidades diversas de aprendizagem (informal, situada, colaborativa e na prática), que induzem à formação das comunidades de prática.

Com isso, nota-se uma falta de clareza no conceito de comunidades de prática, no sentido do termo revelar-se ambíguo, posto que assume mais de um sentido e de uma interpretação, o que é um traço comum em conceitos novos, os quais evoluem desdobrando-se em variações que, com a maturidade, tendem à convergência e à unicidade. Esse processo evolutivo do conceito está refletido nas variações conceituais discutidas anteriormente, as quais, no entanto, são amparadas pela existência deste na colocação de limites em suas apropriações. Apesar da falta de clareza no conceito dado pelos autores tradicionais sobre o que é uma comunidade de prática, as explicações sobre o que essa 
comunidade não é são sempre retomadas. É esse limite nas formas de apropriação que deve ser evidenciado. É a partir desse limite que se devem perceber as transgressões conceituais e suas inerentes deturpações.

\section{Referências}

Amini, A., \& Mortazavi, S. (2012). Effectiveness of psychological capital on mistake management culture as a resource for learning in organization. International Journal of Human Sciences, 9(2), 339-348.

Antonacopoulou, E. P. (2006). The relationship between individual and organisational learning: new insights from managerial learning practices. Management Learning, 37(4), 455-473. doi: $10.1177 / 1350507606070220$

Antonello, C. S., \& Godoy, A. S. (2011). Aprendizagem organizacional e as raízes de sua polissemia. In C. S. Antonello \& A. S. Godoy (Orgs.), Aprendizagem organizacional no Brasil (pp. 31-50). Porto Alegre: Bookman.

Antonello, C. S., \& Ruas, R. (2002, setembro). Formação gerencial: pós-graduação lato sensu e o papel das comunidades de prática. Anais do Encontro Nacional da Associação Nacional de PósGraduação e Pesquisa em Administração, Salvador, BA, Brasil, 26.

Argote, L., \& Miron-Spektor, E. (2011). Organizational learning: from experience to knowledge. Organization Science, 22(5), 1123-1137. doi: 10.1287/orsc.1100.0621

Argyris, C., \& Schon, D. (1996). Organizational learning II: theory, method and practice. New York: Addison-Wesley.

Barab, S., \& Duffy, T. M. (2000). From practice fields to communities of practice. In D. H. Jonassen \& S. M. Land (Eds.), Theoretical foundations of learning environments (pp. 29-64). Mahwah: Lawrence Erlbaum Associates.

Battisti, F. de, \& Salini, S. (2013). Robust analysis of bibliometric data. Statistical Methods \& Applications, 22(2), 269-283. doi: 10.1007/s10260-012-0217-0

Boerner, C. S., Macher, J. T., \& Teece, D. J. (2001). A review and assessment of organizational learning in economic theories. In M. Dierkes, A. Berthoin Antal, J. Child, \& I. Nonaka (Eds.), Handbook of organizational learning and knowledge (pp. 89-117). Oxford: Oxford University Press.

Brown, J. S., \& Duguid, P. (1991). Organizational learning and communities of practice: toward a unified view of working, learning and innovation. Organization Science, 2(1), 40-57. doi: 10.1287/orsc. 2.1 .40

Bunderson, J. S., \& Reagans, R. E. (2011). Power, status, and learning in organization. Organization Science, 22(5), 1182-1195. doi: 10.1287/orsc.1100.0590

Campbell, T. T., \& Armstrong, S. J. (2013). A longitudinal study of individual and organisational learning. Learning Organizational, 20(3), 240-258. doi: 10.1108/09696471311328479

Collen, A. (2012). Knowledge, management, and learning when the context of the organization is planetary. The Learning Organization, 19(4), 369-382. doi: 10.1108/09696471211226716

Cox, A. (2005). What are communities of practice? A comparative review of four seminal works. Journal of Information Science, 31(6), 527-540. doi: 10.1177/0165551505057016 
Cruz, C. C. P., \& Motta, C. L. R. (2006, novembro). Modelo de sistema de reputação para comunidades virtuais. Anais do Simpósio Brasileiro de Informática na Educação, Campinas, SP, Brasil, 28.

Cunha, M. P. (2011). Introdução: the times they are a-changin: a sociedade organizacional à entrada do século XXI. In C. S. Antonello \& A. S. Godoy (Orgs.), Aprendizagem organizacional no Brasil (pp. XI-XXVI). Porto Alegre: Bookman.

Czarniawska, B. (2001). Anthropology and organizational learning. In M. Dierkes, A. Berthoin Antal, J. Child \& I. Nonaka (Eds.), Handbook of organizational learning and knowledge (pp. 118-136). Oxford: Oxford University Press.

Eijkman, H. (2011). The learning organization as concept and journal in the neo-millennial era: a plea for critical engagement. The Learning Organization, 18(3), 164-174. doi: $10.1108 / 09696471111123234$

Ferrara, A., \& Salini, S. (2012). Ten challenges in modeling bibliographic data for bibliometric analysis. Scientometrics, 93(3), 765-785. doi: 10.1007/s11192-012-0810-х

Franceschet, M. (2010). A comparison of bibliometric indicators for computer science scholars and journals on Web of Science and Google Scholar. Scientometrics, 83(1), 243-258. doi: 10.1007/s11192-009-0021-2

Gazzoli, P. (2006, setembro). Comunidades de prática enquanto viabilizadoras de projetos comuns em ambientes turbulentos: uma abordagem crítica. Anais do Encontro Nacional da Associação Nacional de Pós-Graduação e Pesquisa em Administração, Salvador, BA, Brasil, 30.

Gherardi, S. (2001). From organizational learning to practice-based knowing. Human Relations, 54(1), 131-139. doi: $10.1177 / 0018726701541016$

Gherardi, S., \& Nicolini, D. (2001). The sociological foundations of organizational learning. In M. Dierkes, A. Berthoin Antal, J. Child \& I. Nonaka (Eds.), Handbook of organizational learning and knowledge (pp. 35-60). Oxford: Oxford University Press.

Godoy, A. S., \& Antonello, C. S. (2011). Cartografias da aprendizagem organizacional no Brasil: uma visão multiparadigmática. In C. S. Antonello \& A. S. Godoy (Orgs.), Aprendizagem organizacional no Brasil (pp. 51-77). Porto Alegre: Bookman.

Grieves, J. (2008). Why we should abandon the idea of the learning organization. The Learning Organization, 15(6), 463-473. doi: 10.1108/09696470810907374

Gropp, B. M. C. (2003, setembro). De "cascão a lagartixa": uma abordagem etnográfica focada na perspectiva de comunidades de prática em aprendizagem organizacional. Anais do Encontro Nacional da Associação Nacional de Pós-Graduação e Pesquisa em Administração, Atibaia, SP, Brasil, 27.

He, S. L., \& McShane, S. (2010). Structural and informal knowledge acquisition and dissemination in organizational learning: an exploratory analysis. Learning Organization, 17(4), 364-386. doi: $10.1108 / 09696471011043117$

Lapalombara, J. (2001). The underestimated contributions of polit to organizational learning. In M. Dierkes, A. Berthoin Antal, J. Child, \& I. Nonaka (Eds.), Handbook of organizational learning and knowledge (pp. 137-161). Oxford: Oxford University Press.

Lave, J., \& Wenger, E. (1991). Situated learning: legitimate peripheral participation. Cambridge: Cambridge University Press.

LeBaron, B. (2012). Heterogeneous gain learning and the dynamics of asset prices. Journal of Economic Behavior \& Organization, 83(3), 424-445. doi: 10.1016/j.jebo.2012.03.003

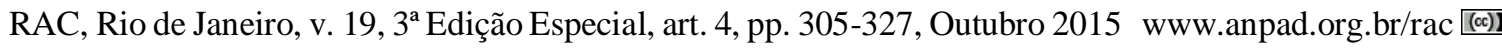


Levitt, B., \& March, J. G. (1988). Organizational learning. Annual Review of Sociology, 14(1), 319-340.

Lui, S. S. (2009). The roles of competence trust, formal contract, and time horizon in interorganizational learning. Organization Studies, 30(4), 333-353. doi: 10.1177/0170840608101139

Mackenzie, C. (2012). Book review: critical concepts in management and organization studies. Management Learning, 43(4), 461-462. doi: 10.1177/1350507612454375

Marchant, T. (2009). An axiomatic characterization of the ranking based on the h-index and some other bibliometric rankings of authors. Scientometrics, 80(2), 325-342. doi: 10.1007/s11192-008-2075-y

Mendes, L., \& Antonello, C. S. (2011). Apropriação indébita? Repensando a utilização da teoria de Michel Foucault nos estudos em aprendizagem organizacional. In C. S. Antonello \& A. S. Godoy (Orgs.), Aprendizagem organizacional no Brasil (pp. 423-439). Porto Alegre: Bookman.

Mengalli, N. M. (2006). Interação, redes e comunidades de prática: subsídios para a gestão do conhecimento na educação (Dissertação de mestrado). Pontifícia Universidade Católica de São Paulo, São Paulo, SP, Brasil.

Mengalli, N. M. (2008). Conceitualização de comunidades de prática (CoP). Recuperado de http://sites.google.com/site/proalexandre/ConceitualizaodeComunidadedePrtica.doc

Pawlowsky, P. (2001). The treatment of organizational learning in management Science. In M. Dierkes, A. Berthoin Antal, J. Child \& I. Nonaka (Eds.), Handbook of organizational learning and knowledge (pp. 61-88). Oxford: Oxford University Press.

Ribes, D., \& Bowker, G. C. (2009). Between meaning and machine: learning to represent the knowledge of communities. Information and Organization, 19(4), 199-217. doi: 10.1016/j.infoandorg.2009.04.001

Roediger, H. L., III, \& McDermott, K. B. (1999). False alarms and false memories. Psychological Review, 106(2), 406-410. doi: 10.1037/0033-295X.106.2.406

Sanz, S. (2005). Comunidades de práctica virtuales: acceso y uso de contenidos. Revista de Universidad y Sociedad del Conocimiento, 2(2), 213-231.

Silverman, D. (2010). Um livro bom, pequeno e acessível sobre pesquisa qualitativa. Porto Alegre: Bookman.

Silvio, J. (1999). Las comunidades virtuales como conductoras del aprendizaje permanente. Recuperado de http://funredes.org/mistica/castellano/ciberoteca/participantes/docuparti/esp_doc_31.html

Svensson, L., \& Doumas, K. (2013). Contextual and analytic qualities of research methods exemplified in research on teaching. Qualitative Inquiry, 19(6), 441-450. doi: 10.1177/1077800413482097

Tremblay, D. G. (2004). Communities of practice: are the organizational conditions for implementation the same for a virtual multiorganization community? Revista Organizações \& Sociedade, 11(31), 25-39. doi: 10.1590/S1984-92302004000300002

Watkins, K. E., \& Marsick, V. J. (1992). Toward a theory of informal and incidental learning in organizations. International Journal of Lifelong Education, 11(4), 287-300. doi: $10.1080 / 0260137920110403$

Wenger, E. (1998). Communities of practice: learning, meaning, and identity. Cambridge: Cambridge University Press. 
Wenger, E. (2003). Communities of practice and social learning system. In D. Nicolini, S. Gherardi, \& D. Yanow (Eds.), Knowing in organizations: a practice-based approach (pp. 76-99). New York: ME Sharpe.

Wenger, E., McDermontt, R., \& Snyder, W. M. (2002). Cultivating communities of practice. Boston: Harvard Business School Press.

Wenger, E., \& Snyder, W. M. (2001). Comunidades de prática: a fronteira organizacional (Coleção Harvard Business Review de aprendizagem organizacional). Rio de Janeiro: Campus.

Yakhlef, A. (2010). The corporeality of practice-based learning. Organization Studies, 31(4), 409-430. doi: $10.1177 / 0170840609357384$

\section{Dados dos Autores}

Luciano Mendes

Avenida Pádua Dias, 11, São Dimas, 13418-900, Piracicaba, SP, Brasil. E-mail: mendes@usp.br

Ligia Maria Soto Urbina

Praça Marechal Eduardo Gomes, 50, Vila das Acácias, 12228-900, São José dos Campos, SP, Brasil. E-mail: ligia@ita.br 